\title{
Processos criativos na pintura contemporânea: da pesquisa à sala de aula
}

Procesos creativos

en pintura contemporánea:

de la investigación a la sala

de clase.

Priscilla de Paula Pessoa

Eluíza Bortolotto Ghizzi

1 Priscilla de Paula Pessoa (UFMS) bacharel em Artes Visuais, mestre em Estudos de Linguagens e doutoranda em Estudos de Linguagens (UFMS). É professora adjunta nos cursos de Artes Visuais/UFMS, nas áreas de História da Arte e Pintura, com pesquisa sobre processos criativos na pintura. É também artista visual, tendo participado de diversas exposições individuais e coletivas Lattes: http://lattes.cnpq.br/5515291284729264 E-mail: priscilla.pessoa@ufms.br

²Eluíza Bortolotto Ghizzi (UFMS) Arquiteta, doutora em Comunicação e Semiótica (PUCSP/bolsa CAPES), docente no Programa de Pós-graduação em Estudos de Linguagens da UFMS, membro do Centro de Estudos de Pragmatismo (PUCSP/ CNPq) e pesquisadora da filosofia e da semiótica pragmatistas de Charles S. Peirce, com ênfase nas suas aplicações à arte e à arquitetura.

Lattes: http://lattes.cnpq.br/5923072329013624

E-mail: eluizabortolotto.ghizzi@gmail.com 


\section{Resumo}

O artigo aborda a interação entre pesquisa e ensino na disciplina Oficina de Pintura II, oferecida nos cursos de Artes Visuais/UFMS, em 2017. A autora principal ministrou a disciplina e coordenou o projeto de pesquisa Processos Criativos na Pintura Contemporânea - Teoria e Prática, na mesma instituição. Apresenta-se primeiramente o projeto, que tem como objetivo fazer um levantamento das possibilidades da pintura contemporânea enfocando o processo criativo de pintores em evidência no circuito de arte nacional. Em seguida, a ementa, o programa e os objetivos da disciplina são colocados em pauta. Por fim, é feita uma análise sobre como as investigações realizadas dentro da pesquisa foram aplicadas no plano de ensino e nas aulas, tomando como exemplo um recorte da abordagem feita sobre o papel dos arquivos no processo criativo de pinturas, com base na diferenciação entre arquivos proposta por Cecília Salles e na apresentação de um registro de processo do artista Eduardo Berliner.

\section{Palavras-chave}

Pintura; Ensino Superior; Processos Criativos

\section{Resumen}

El artículo abordala interacción entre la investigación y la enseñanza en la disciplina Taller de pintura II, ofrecida en los cursos de Artes visuales /UFMS, en 2017. La autora principal enseñó la disciplina y coordinó el proyecto de investigación Procesos creativos en pintura contemporánea: teoría y práctica, en la misma institución. Primero, se presenta el proyecto, que tiene como objetivo estudiar las posibilidades de la pintura contemporánea centrándose en el proceso creativo de pintores en evidencia en el circuito nacional de arte. Luego, el menú, el programa y los objetivos de la disciplina se colocan en la agenda. Finalmente, se hace un análisis de cómo se aplicaron las investigaciones realizadas dentro de la investigación en el plan de enseñanza y en las clases, tomando como ejemplo una parte del enfoque adoptado sobre el papel de los archivos en el proceso creativo de las pinturas, basado en la diferenciación entre archivos propuesta por Cecília Salles y en la presentación de un registro de proceso del artista Eduardo Berliner.

\section{Palabras clave}

Pintura; Enseñanza Superior; Procesos Creativos

ISSN: 2447-1267 


\section{Introdução}

Na contemporaneidade paira sempre sobre a pintura o questionamento acerca de sua permanência frente a tantos outros meios disponíveis aos artistas. Porém, tal situação não ocorre em Mato Grosso do Sul: a pintura reina absoluta na arte local, sendo maciça sua presença tanto histórica como atual, e como coloca Menegazzo (2013, p.14), "é evidente a supremacia da pintura como linguagem da arte sulmato-grossense". A questão que se apresenta então ao artista no cenário sul-matogrossense não é, portanto, sustentar sua escolha pelas tintas - ela é quase natural; o grande desafio é revelar como a pintura é contagiada pelo pensamento de seu tempo e como segue forte, refletindo as questões da própria arte contemporânea.

Tal desafio não se limita ao trabalho do artista que faça a opção pela pintura, mas também se estende ao docente que trabalha com disciplinas ligadas à linguagem, especialmente no ensino superior em Artes Visuais: como abordar a prática pictórica considerando-a sempre sob a perspectiva de uma longa tradição, mas principalmente, como uma linguagem da arte contemporânea? Como lidar, para além da amplitude de possibilidades que a pintura oferece, também com as especificidades de cada acadêmico, muitas vezes na posição de artistas em formação? Dentre as várias estratégias possíveis e efetivamente aplicadas com o intuito de trabalhar estas questões na disciplina Oficina de Pintura II dos cursos de Artes Visuais da UFMS (ministrada pela autora principal do presente texto) no ano de 2017, são abordados aqui especificamente proposições e registros de experiências relativos à aplicação das investigações advindas da pesquisa Processos Criativos na Pintura Contemporânea Teoria e Prática, no plano de ensino e no andamento da disciplina. O processo criativo é aqui entendido a partir da perspectiva de Ostrower (1993, p.07), para quem:

\footnotetext{
A natureza criativa do homem se elabora no contexto cultural. Todo indivíduo se desenvolve em uma realidade social, em cujas necessidades e valorações culturais se moldam os próprios valores de vida. No indivíduo confrontamse, por assim dizer, dois pólos de uma mesma relação: a sua criatividade que representa as potencialidades de um ser único, e sua criação que será a realização dessas potencialidades já dentro do quadro de determinada cultura.
}

Quando o projeto de pesquisa foi elaborado, já trazia em seu cerne a intenção de contribuir com o caldo de referências que cada estudante traz de seus contextos sociais, adicionando a este repertório contato e reflexão sobre o processo criativo de pintores brasileiros que têm tido destaque no circuito nacional de arte contemporânea, expandindo sua noção sobre como pode dar-se o percurso que leva a uma produção, para além das experiências pessoais, mas também a partir da experiência do outro. Desde o início do projeto, em 2015, foi iniciado intenso diálogo entre a pesquisa e o ensino, prática fortemente incentivada pela UFMS e sobre o qual apresenta-se, a seguir, breves apontamentos. 


\section{Projeto de Pesquisa Processos Criativos na Pintura Contemporânea - Teoria e Prática}

A pesquisa, desenvolvida entre 2015 e 2019 pela autora principal do presente texto, teve como objetivo fazer um levantamento das amplas possibilidades e desafios da pintura contemporânea, enfocando principalmente o processo criativo de pintores brasileiros em evidência no circuito de arte nacional. $O$ estudo do processo criativo feito a partir dos registros gerados pelo artista sobre a produção de sua obra está embasado na chamada Crítica Genética ${ }^{1}$, abordagem utilizada na pesquisa; de origem francesa, o termo refere-se à linha investigativa que pretende indagar a obra de arte a partir de sua gênese. Segundo Salles (2004), documentos do processo são todo tipo de vestígio (registros visuais, textos, entrevistas, etc.) deixados pelo artista durante e após o processo de criação de uma obra ou de um conjunto delas; na relação entre os registros e a obra entregue ao público, encontramos o pensamento em processo.

Os artistas que tiveram seus processos investigados (muitas vezes com a colaboração dos mesmos) foram selecionados a partir de um recorte obtido com o levantamento daqueles que trabalham com a linguagem da pintura e têm participação recorrente, nas duas primeiras décadas do século XXI, em importantes eventos do circuito de arte contemporânea brasileiro, a saber: salões de arte contemporânea de todas as regiões (de Anápolis/GO, do Pará, de Ribeirão Preto/SP, do Paraná e do Ceára), prêmios (PIPA, Marcantônio Vilaça, Itaú Cultural), exposições individuais em museus de arte contemporânea (em todo o país). Tomando como base esse amplo e constante levantamento, chegou-se a mais de uma centena de nomes, a partir dos quais foram escolhidos os processos criativos que seriam objeto da pesquisa em seus primeiros dois anos de atividade, tendo como critério principal nessa escolha a maior diversidade possível de caminhos da criação em pintura.

Assim, entre 2015 e 2016 a pesquisa coletou dados sobre o processo criativo de oito artistas, buscando todo o material que desse conta das etapas, nuances e mudanças nos percursos que geraram suas pinturas recentes, mas fazendo a análise com ênfase especial em um procedimento específico de cada: na maneira como Ana Elisa Egreja (1983) faz uso de imagens encontradas na internet como referência para sua produção; no arquivo de materiais que porventura possam entrar nas pinturas de Eduardo Berliner (1978); no papel fundamental das pesquisas teóricas sobre história, religião e política na conceituação das séries de Evandro Prado (1985); na recuperação de memórias e afetividades na concepção das imagens de Fábio Barolli (1981); na importância da produção de fotografias autorais como referência para Fábio Magalhães (1982); nos caminhos entre observação e abstração percorridos por Gabriela Machado (1960); nas telas já contendo elementos pictóricos e que são o ponto de partida para a pintura de Lucia Laguna (1941); e na repercussão de condições

1 Inicialmente ligado à literatura, este termo é hoje aplicado para discutir o processo criativo em outras manifestações artísticas. 
pessoais na obra de forte cunho social e político de Sidney Amaral (1973-2017).

Tal material, em seu estado bruto (esboços, referências fotográficas e arquivos diversos, além de entrevistas e depoimentos concedidos pelos artistas), foi discutido em encontros de grupo de estudo vinculado à pesquisa e tem servido de base para a produção de textos que se debruçam sobre os processos dos referidos artistas. Mas, para além da produção científica, a aplicabilidade pedagógica da pesquisa é outro viés importante de sua realização, tendo como principal espaço de vinculação as Oficinas de Pintura dos cursos de Artes Visuais da UFMS (licenciatura e bacharelado), como exposto a seguir.

\section{Abordagem da Pesquisa no plano de ensino da Oficina de Pintura II em 2017}

A Oficina de Pintura II, em 2017, tinha a seguinte ementa, determinada na estrutura curricular do Projeto Pedagógico do curso de Artes Visuais/Bacharelado da UFMS (2015): "Pesquisas práticas concernentes aos materiais, técnicas e suportes usados em pintura, buscando soluções plásticas e considerando a linguagem pictórica como manifestação contemporânea na elaboração de uma poética individual". Tratase de uma disciplina de aprofundamento, uma vez que é antecedida e tem como pré-requisitos o cumprimento de Pintura I, Pintura II e Oficina de Pintura I. Está entre as disciplinas optativas eletivas oferecidas tanto para a licenciatura como para o bacharelado, ou seja, o acadêmico tem a opção de escolher ou não cursá-la para aprofundar-se na linguagem.

O projeto de ensino desenvolvido para a disciplina considera fortemente a singularidade da produção pictórica de cada acadêmico, não só em relação ao conjunto de obras resultantes, mas entendendo que cada caminhar que levou à sua criação é também uma sequência de procedimentos singulares. Como coloca Salles (2002, p.191):

A criação mostra-se como uma metamorfose contínua. É um percurso feito de formas em seu caráter provisório e precário porque hipotético. O percurso criador é um contínuo processo de transformação buscando a formatação da matéria de uma determinada maneira e com um determinado significado. Processo este que acontece no âmbito de um projeto estético e ético e cujo produto é uma realidade nova.

Oportunamente, retorna-se ao questionamento colocado na introdução: como lidar, para além da amplitude de possibilidades que a pintura oferece, também com as especificidades de cada acadêmico, muitas vezes na posição de artistas em formação? Pensando nisso, foram definidos no plano de ensino os objetivos e o programa da disciplina: 


\begin{tabular}{|l|l|}
\hline \multicolumn{1}{|c|}{ OBJETIVOS } & \multicolumn{1}{c|}{ PROGRAMA } \\
\hline $\begin{array}{l}\text { 1. Adquirir um conjunto de conhecimentos } \\
\text { sobre a pintura na arte contemporânea; }\end{array}$ & $\begin{array}{l}\text { 1. Aulas expositivas e discussões em grupo } \\
\text { sobre referências em pintura contemporânea } \\
\text { e processos criativos. }\end{array}$ \\
\hline
\end{tabular}

\begin{tabular}{|l|l|l|}
\hline 2. Pesquisar materiais, suportes e outros & 2. Experimentações coletivas com materiais \\
recursos utilizáveis em pintura; & e suportes não tradicionais em pintura. \\
3.Conhecer diversos processos criativos de & 3.Concepção orientada de projeto "vivo" \\
artistas contemporâneos que trabalham com & para série de pinturas. \\
pintura. & 4.Realização orientada de pinturas. & \\
4.Desenvolver projetos individuais em pintura & 5.Construção orientada de texto de \\
envolvendo pesquisa, proposta poética & apresentação. & \\
e execução, com ênfase nas tendências & & \\
contemporâneas da linguagem. & & \\
\end{tabular}

Especialmente por causa do terceiro objetivo e do primeiro item do programa, estabelece-se a relação pesquisa/ensino: a reflexão proposta ao acadêmico (em torno da produção artística que investiga a pintura na arte contemporânea) tem sua ênfase muito mais no bastidor do processo criativo dos artistas do que na análise das obras resultantes. Parte-se da premissa que, dada justamente a amplitude de possibilidades de caminhares aberta para a criação em pintura, é impossível ensinar um modelo de processo criativo, mas pode ser muito construtivo apresentar e discutir os variados processos de artistas, enriquecendo o repertório do acadêmico sobre procedimentos e estratégias.

Ressalta-se ainda que a aplicação do programa não é sequencial e sim intercalada, de forma que a discussão permeia o decorrer de todo o semestre. Como exemplo da aplicabilidade de produtos da pesquisa no plano de ensino e na prática pedagógica da disciplina, vejamos como as investigações sobre o arquivismo no processo criativo em pintura foram trabalhadas em sala de aula.

\section{Discussão do arquivismo a partir do processo criativo do artista Eduardo Berliner}

No início da Oficina de Pintura II um dos textos proposto para leitura e discussão aos acadêmicos foi o artigo Arquivos nos processos de criação contemporâneos, de autoria de Cecília Salles (2012). O texto, como a própria autora coloca, é um mapeamento ainda embrionário sobre arquivos de artistas contemporâneos; é filiado à crítica genética e voltado principalmente para críticos, mas, durante o planejamento da disciplina, entendeu-se que seria uma valiosa base teórica para introduzir artistas em formação a uma etapa do processo criativo tão marcante na produção atual e 
que, ao mesmo tempo, detectou-se quase inexistente entre suas práticas, conforme informado pelos mesmos: dos 31 estudantes matriculados apenas cinco mantinham, no início do semestre, o arquivamento de materiais como parte consciente de seus processos.

No texto a autora detecta algumas constantes observadas nos arquivos que acompanham o percurso da produção de obras de arte e define assim os principais papeis que desempenham ao longo do processo criador: "armazenamento e experimentação."

O artista encontra os mais diversos meios de armazenar informações, que atuam como auxiliares no percurso de concretização da obra e que nutrem o artista e a obra em criação. $O$ ato de criar provisões é geral, está sempre presente nos documentos de processo; no entanto, aquilo que é guardado e como é registrado varia de um processo para outro, até de um mesmo artista. Outra função desempenhada pelos documentos de processos é a de registro de experimentação, deixando transparecer a natureza indutiva da criação. Nesse momento de concretização da obra, hipóteses de naturezas diversas são levantadas e testadas. São documentos privados responsáveis pelo desenvolvimento da obra. São possibilidades de obras. Sob essa perspectiva, são registros da experimentação sempre presente no ato criador, encontrados em rascunhos, estudos, croquis, plantas, esboços, roteiros, maquetes, copiões, projetos, ensaios, contatos, story-boards. (SALLES, 2012, p.751)

Partindo das discussões geradas pelo artigo, foi solicitado aos acadêmicos o início (ou continuidade) de um arquivo pessoal voltado para sua produção artística e, mais especificamente, para o projeto em pintura a ser desenvolvido por cada um deles no semestre, de acordo com o programa da disciplina. Todos os já citados artistas, cujos processos de criação em pintura foram investigados na pesquisa Processos Criativos na Pintura Contemporânea - Teoria e Prática, apresentam o arquivismo como prática, havendo assim um vasto material coletado a respeito; todavia, as análises desses materiais apontam que há grandes variações de um artista para outro tanto na natureza dos arquivos que coletam como também na relação que estabelecem com esse material durante seus processos criativos.

Assim, voltando à sala de aula, além das elucidações sobre o tema que a leitura trouxe, procurou-se apresentar aos acadêmicos exemplos variados de arquivos de armazenamento e experimentação e, nesse momento, entra em ação efetiva a aplicação de elementos da pesquisa no desenvolvimento da disciplina: optou-se por levar à aula uma seleção breve mas representativa dos registros coletados (entrevistas, imagens, vídeos) perfazendo um recorte do arquivismo no processo das pinturas de artistas contemporâneos como Ana Elisa Egreja, Fabio Magalhães, Gabriela Machado, Lucia Laguna, entre outros. Dentro dessa seleção, relata-se a seguir, à guisa de exemplo de procedimentos metodológicos, o uso dos levantamentos feitos sobre os arquivos de Eduardo Berliner ${ }^{2}$. 
Entre os diversos materiais levantados sobre Berliner, foi apresentado e discutido com os acadêmicos um episódio do programa Catálogo (2010), que visita o ateliê do artista e toma seu depoimento justamente sobre os procedimentos que desembocam em suas pinturas. Tal proposição não pretende dar conta da complexidade do processo criativo de Berliner, mas a fala do artista deixa entrever diversas vezes a relação estabelecida com seus arquivos, e esse viés especificamente foi enfocado; a frase dita pelo artista que dá início ao vídeo já estabelece coincidentemente esse recorte: "Eu costumo trabalhar coletando, registrando minhas impressões do mundo: coisas que eu vejo, coisas que eu ouço". É possível ver em muitos momentos seus cadernos (Fig. 1), repletos de anotações, desenhos e colagens.

Além dos cadernos, o artista afirma ainda que costuma portar sempre uma câmera fotográfica e no vídeo podemos observar paredes repletas de fotografias de sua autoria (Fig.2); pequenos objetos descartados, que cruzaram seu cotidiano, também são por ele coletados e arquivados. Berliner (2010) situa tais materiais na condição não de referências produzidas especificamente para a concepção de determinada pintura, mas como arquivos de armazenamento: "tem vezes em que eu não sei na hora o que estou fazendo. Tem vezes em que eu realmente fico curioso com aquilo, mexido com aquilo de alguma forma, mas não tenho certeza absoluta."

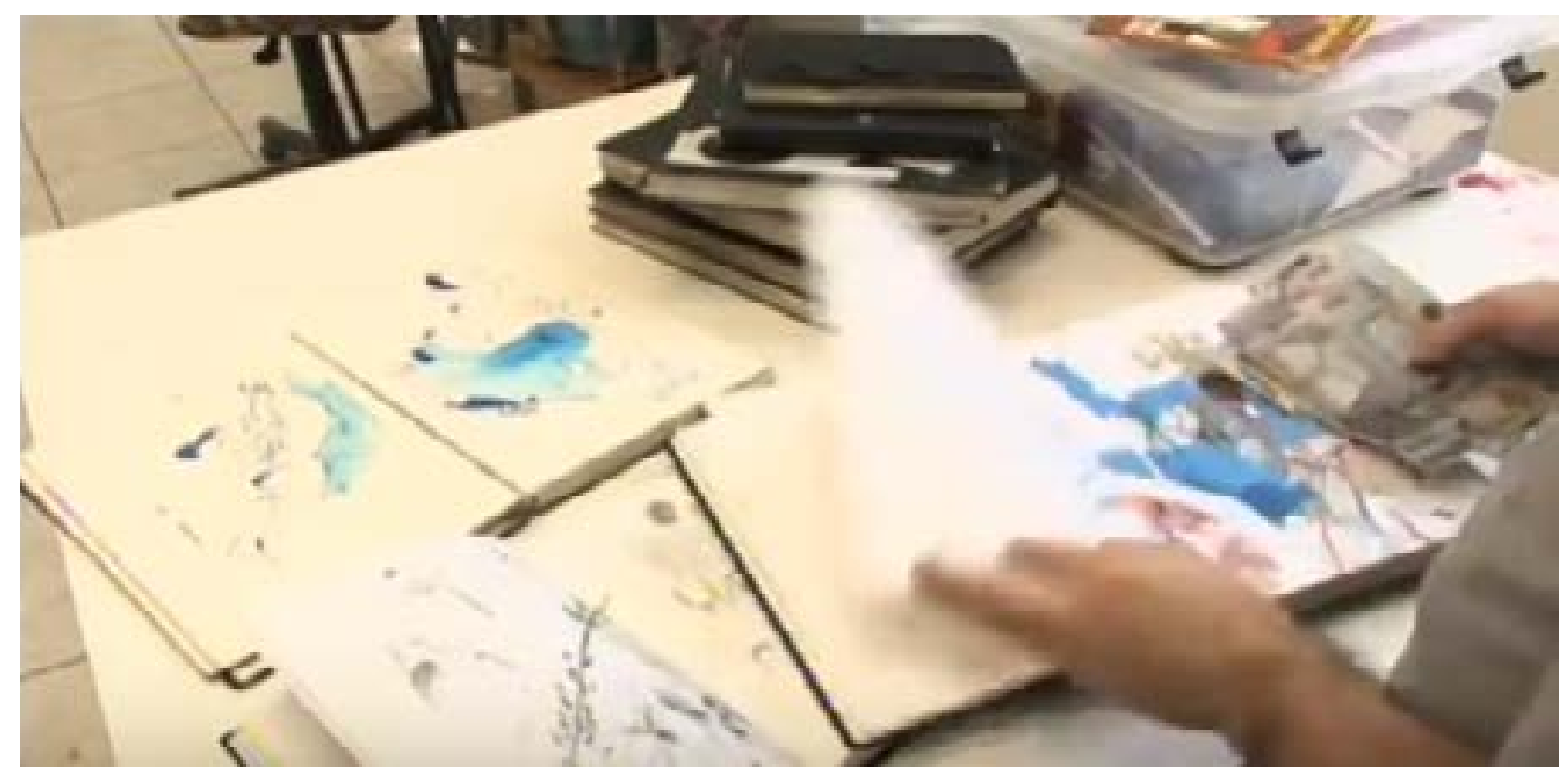

Fig. 1. Captura de imagem do episódio do programa Catálogo sobre Eduardo Berliner. Fonte: CATÁLOGO (2010)

circuito de arte contemporânea nacional desde o ano 2000, com participação em vários dos eventos a partir dos quais a pesquisadora seleciona artistas para suas análises, como Prêmio Marcantônio Vilaça (2010), Prêmio Pipa (2010, 2011 e 2014), Salão de Arte de Ribeirão Preto (2005), além da Bienal de São Paulo (2012). 


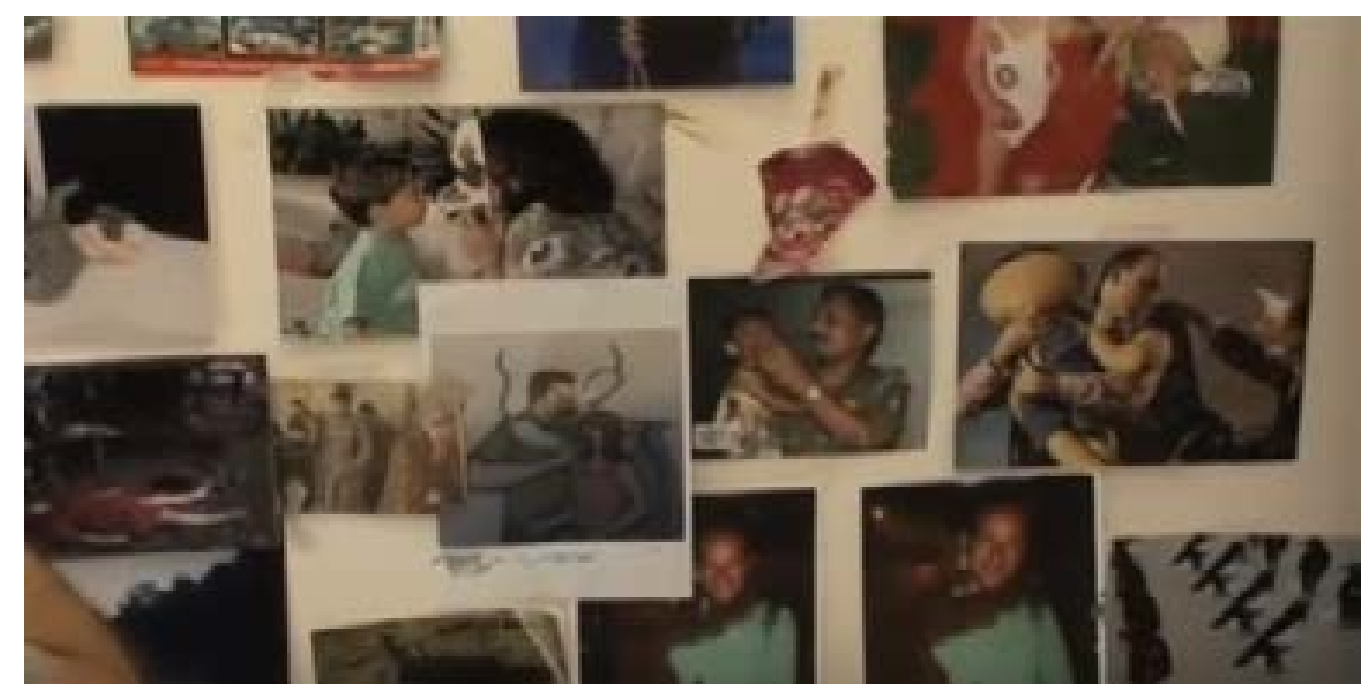

Fig. 2. Captura de imagem do episódio do programa Catálogo sobre Eduardo Berliner Fonte: CATÁLOGO (2010)

É possível ainda acompanhar, no decorrer do vídeo, exemplos de um segundo momento da relação de Berliner com os materiais que armazena: quando seleciona desenhos ou fotografias para referenciar suas pinturas e, mais importante ainda, a maneira como os utiliza. $\bigcirc$ artista fala sobre isso, mostrando uma fotografia (Fig. 3) de arquivo tomada como base para uma de suas pinturas (Fig. 4):

Aqui, por exemplo, eu ia fazer um quadro que ía ser assim. Mas quando eu comecei a fazer esse quadro eu abri mão do plano inicial e trouxe só esse elemento, esse homem. Então esse quadro foi andando de um jeito diferente, eu não tinha só esse plano inicial, tinha vários elementos soltos que eu fui unindo durante o processo de pintura; então ele acaba tendo um clima diferente mesmo, porque o próprio processo determinou isso. (BERLINER, 2010)

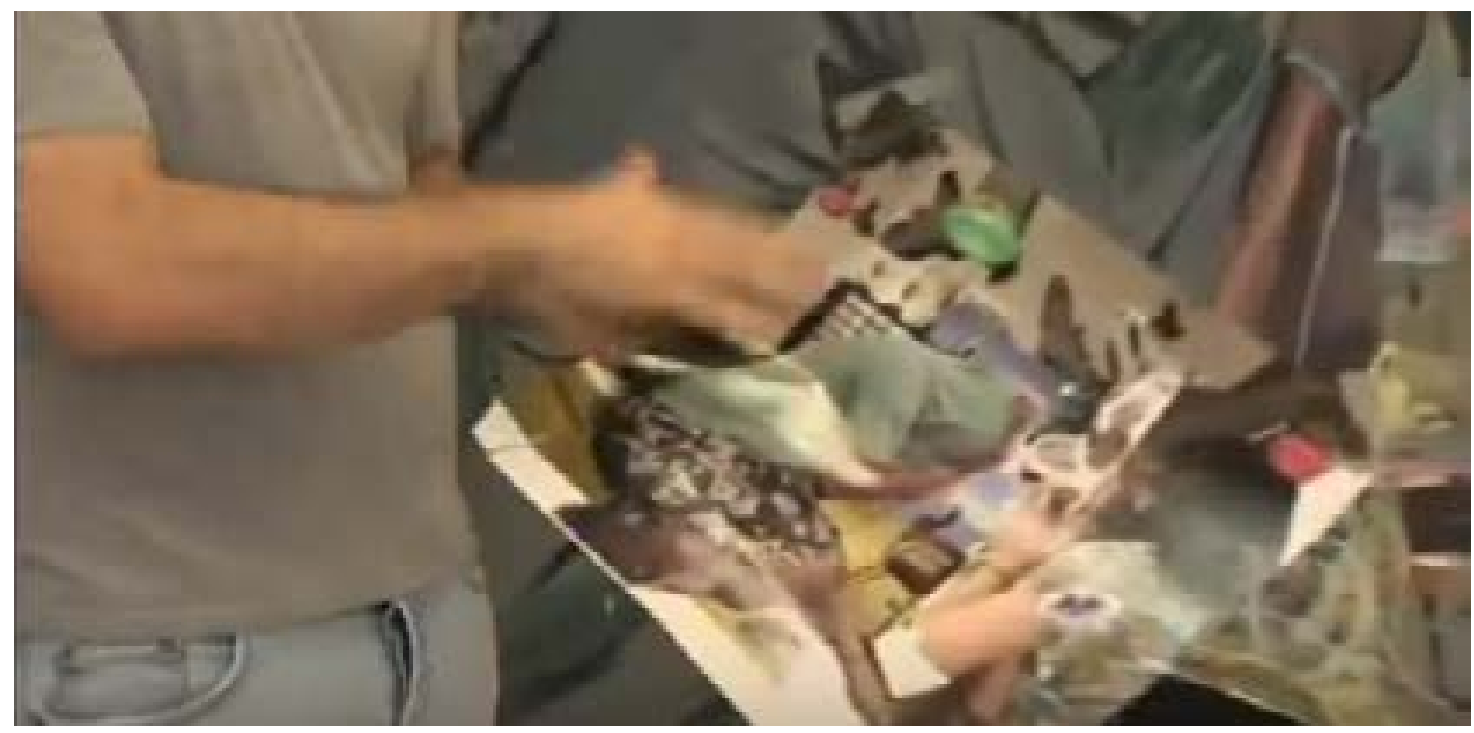

Fig. 3. Captura de imagem do episódio do programa Catálogo sobre Eduardo Berliner Fonte: CATÁLOGO (2010) 


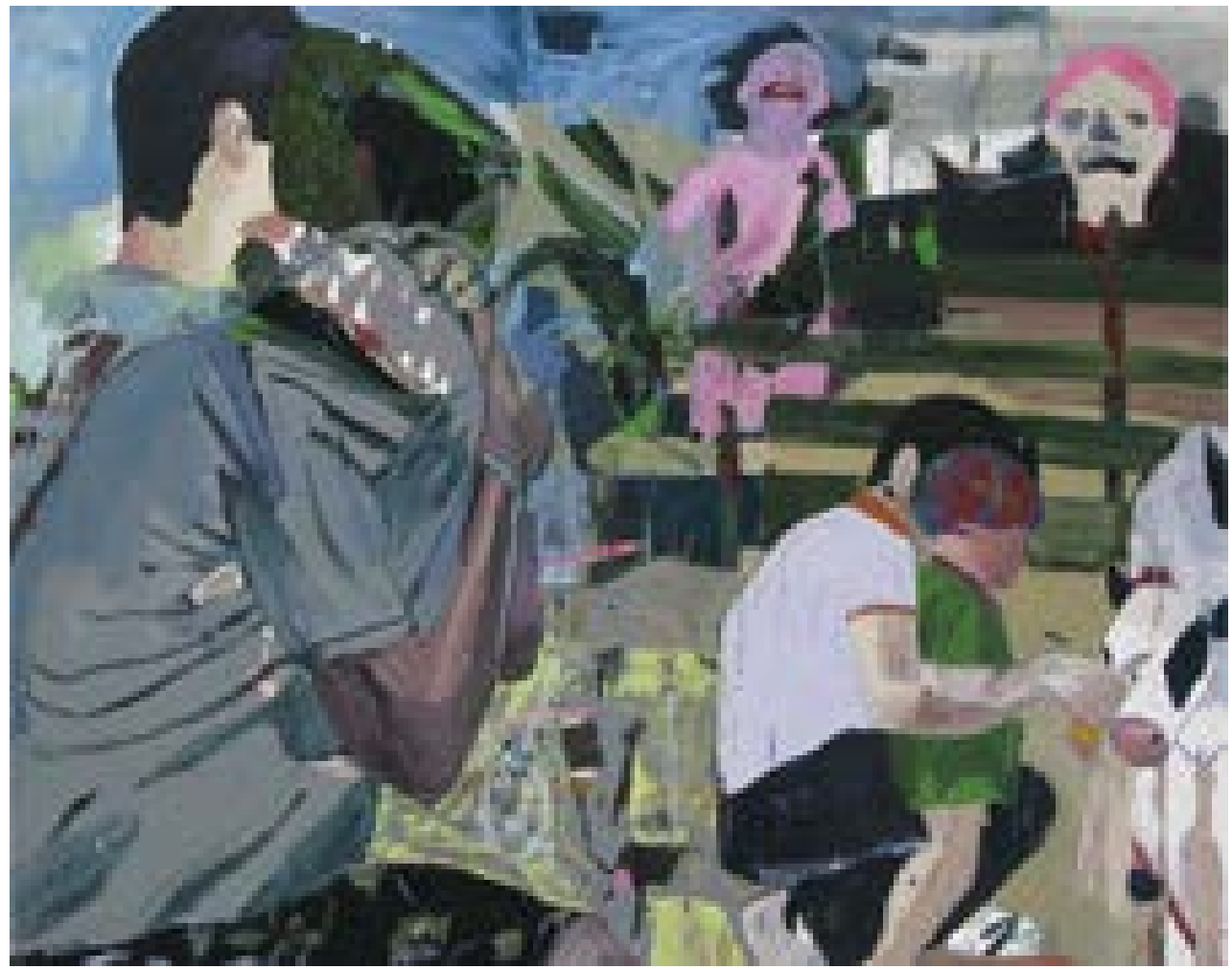

Fig. 4. Captura de imagem do episódio do programa Catálogo sobre Eduardo Berliner. Fonte: CATÁLOGO (2010)

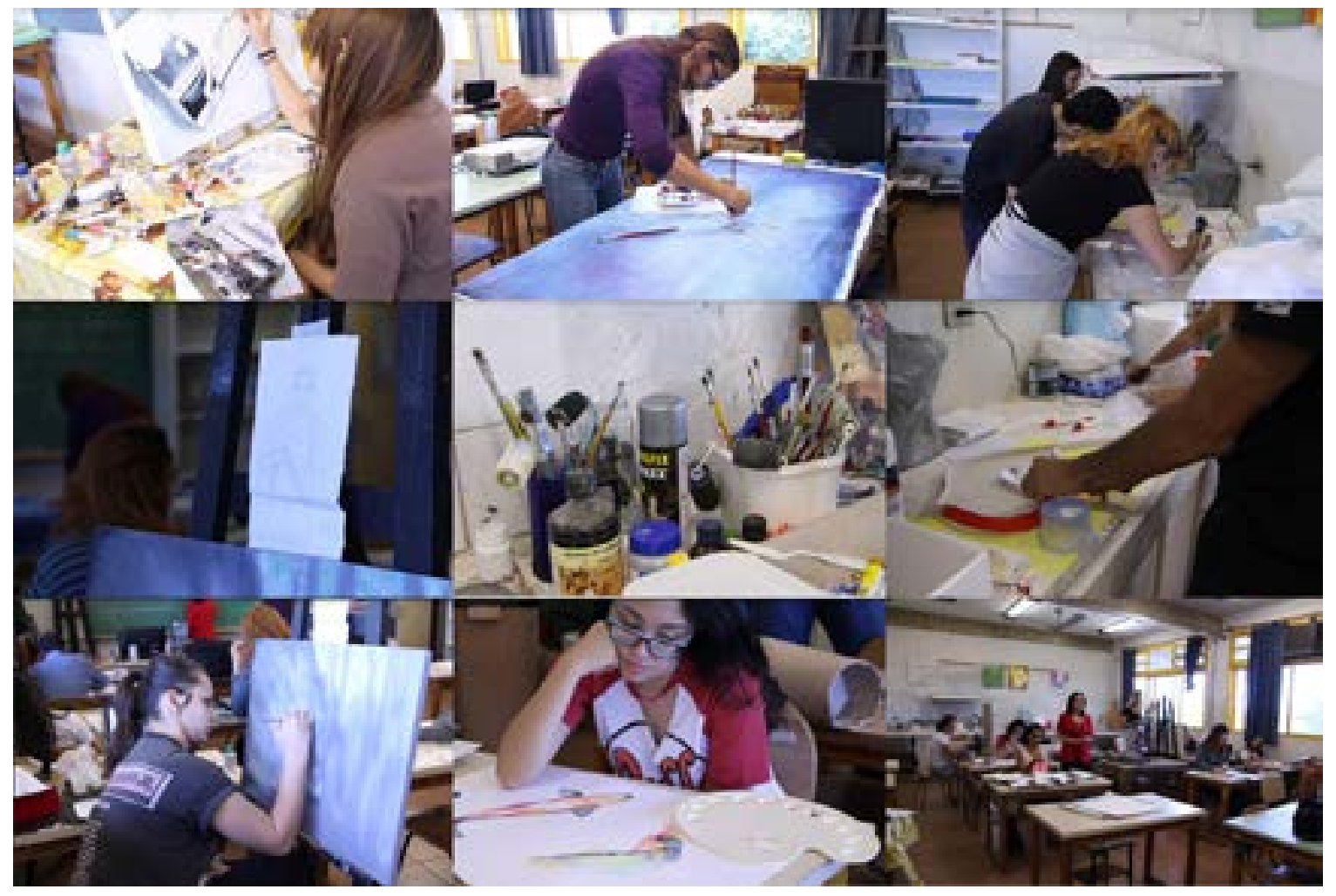

Fig. 5. Compilação de registros fotográficos feitos pela acadêmica Amanda Mamede na Oficina de Pintura II. Fonte: Arquivo pessoal da autora. 
Passando-se às discussões advindas da exibição do vídeo em sala de aula (direcionadas aos arquivos) foi interessante perceber, nas colocações dos alunos da disciplina, como muitos identificaram em suas práticas a manutenção de um caderno ou material similar onde faziam desenhos (seja por inciativa pessoal ou por proposição de algum docente). Mas tal material não é no mais das vezes identificado como um arquivo de armazenamento, de ideias a serem retomadas e desenvolvidas, e sim como uma atividade de "treino" que se encerra em si. Outra identificação foi com o arquivamento de fotografias (geralmente armazenadas por eles em suas redes sociais) como sendo também um material com potencial para servir de alguma forma no processo criativo de suas pinturas.

Foi possível, ainda, traçar com os acadêmicos paralelos entre o modo como Berliner lida com os desenhos e fotografias e caminhos diferentes adotados por outros artistas analisados: alguns produzem desenhos (esboços) ou fotografias de referência já como possibilidade consciente de obra, dentro do que Salles (2012, p.751) considera como arquivos de experimentação, e, ainda, utilizando-os à risca, sem grandes mudanças no projeto durante a execução da pintura; há ainda artistas que valem-se dos dois tipos de arquivamento em seus processos e outros (mais raros) que não mantêm arquivo nenhum.

Nesse momento da discussão, é importante uma intervenção pedagógica da professora apontando duas questões presentes nos paralelos que foram surgindo ao comparar artistas: a variedade de percursos possíveis em um processo criativo e a inexistência de um modelo "certo" ou "errado" para a criação.

Assim, tomar contato com os procedimentos de arquivo de Eduardo Berliner e de vários outros artistas abriu aos acadêmicos um leque de possibilidades em relação aos próprios arquivamentos que eles deveriam fazer.

\section{Considerações Finais}

Assim como o processo criativo de uma obra de arte, também os rumos de uma pesquisa ou a condução de uma disciplina são abertos a possibilidades e escolhas variadas, mudanças de percurso, construções e reconstruções.

que aqui se apresentou foi uma breve descrição sobre o andamento do projeto Processos Criativos na Pintura Contemporânea e sobre como conhecer e analisar os procedimentos de artistas pode contribuir com os estudantes na reflexão e aprofundamento dos seus próprios processos, numa simbiose entre pesquisa e ensino. Tratou-se apenas de um recorte, um exemplo isolado de atividade numa turma específica, mas é importante ressaltar a escolha da professora e pesquisadora por permear toda a aplicação do plano de ensino de suas disciplinas pela ênfase no processo criativo como pilar da produção de pinturas; Processos criativos que se pretende sejam intensos, apaixonados, dinâmicos, e, ao mesmo tempo, absolutamente individualizados. 


\section{Referências}

MENEGAZZO, Maria Adélia. Texto de Apresentação. In: PELLEGRINI, Fabio; REINO, Daniel (Orgs.). Vozes das Artes Plásticas. Campo Grande: Fund. de Cultura de MS, 2013.

OSTROWER, Fayga. Criatividade e processos de criação. $9^{a}$ ed. Petrópolis: Vozes, 1993.

FACULDADE DE ARTES, LETRAS E COMUNICAÇÃO DA UFMS. Projeto Pedagógico do Curso de Artes Visuais. Campo Grande, MS, 2015.

BERLINER, Eduardo. Entrevista concedida a Marcos Ribeiro em 2010. In: CATÁLOGO. Eduardo Berliner. Programa de TV. Rio de Janeiro, RJ: Canal Brasil, 2010. Disponível em: https://www. youtube.com/watch?v=YER6ZYUyAFQ. Acesso em 10 de julho de 2017.

SALLES, Cecília. Arquivos nos processos de criação contemporâneos. In: $21^{\circ}$ Congresso da Associação Nacional de Pesquisadores em Artes Plásticas - ANPAP, Anais [...]. Rio De Janeiro, RJ. 2012. Disponível em: http://www.anpap.org.br/anais/2012/. Acesso em 05 de julho de 2017. p. 750-762.

SALLES, Cecília Almeida - Crítica Genética e Semiótica - Uma interface possível In: ZULAR, Roberto (Org.) Criação em processo: ensaios de crítica genética. São Paulo, SP: Iluminuras. p. 177-201. 2002.

SALLES, Cecília. Gesto inacabado: processo de criação. São Paulo, SP: Fapesp, 2004. 